\title{
Towards understanding the electrodynamics of the 3-dimensional high-latitude ionosphere: present and future
}

 \\ A. Yoshikawa ${ }^{8}$ \\ ${ }^{1}$ Finnish Meteorological Institute, Arctic Research unit, P.O. Box 503, 00101 Helsinki, Finland \\ ${ }^{2}$ Atmospheric Physics Laboratory, UCL, Gower Street, London WC1E 6BT, UK \\ ${ }^{3}$ Swedish Institute of Space Physics, 75121 Uppsala, Sweden \\ ${ }^{4}$ Solar-Terrestrial Environment Laboratory, Nagoya University, Furo-cho, Chikusa-ku, Nagoya, 464-8601, Japan \\ ${ }^{5}$ Applied Physics Laboratory, Johns Hopkins University, 11100 Johns Hopkins Road, Laurel, MD 20723-6099, USA \\ ${ }^{6}$ Cooperative Institute for Research in Environmental Science, University of Colorado, Boulder, CO, 80309, USA \\ ${ }^{7}$ GeoForschungsZentrum (GFZ) Potsdam, Telegrafenberg, 14473 Potsdam, Germany \\ ${ }^{8}$ Department of Earth and Planetary Sciences, Faculty of Science, Kyushu University 33, 6-10-1 Hakozaki, Higashi-ku, \\ Fukuoka 812, Japan
}

Received: 17 March 2008 - Revised: 3 September 2008 - Accepted: 21 October 2008 - Published: 5 December 2008

\begin{abstract}
Traditionally, due to observational constraints, ionospheric modelling and data analysis techniques have been devised either in one dimension (e.g. along a single radar beam), or in two dimensions (e.g. over a network of magnetometers). With new upcoming missions like the Swarm ionospheric multi-satellite project, or the EISCAT 3-D project, the time has come to take into account variations in all three dimensions simultaneously, as they occur in the real ionosphere. The link between ionospheric electrodynamics and the neutral atmosphere circulation which has gained increasing interest in the recent years also intrinsically requires a truly 3 -dimensional (3-D) description. In this paper, we identify five major science questions that need to be addressed by 3-D ionospheric modelling and data analysis. We briefly review what proceedings in the young field of 3-D ionospheric electrodynamics have been made in the past to address these selected question, and we outline how these issues can be addressed in the future with additional observations and/or improved data analysis and simulation techniques. Throughout the paper, we limit the discussion to high-latitude and mesoscale ionospheric electrodynamics, and to directly data-driven (not statistical) data analysis.
\end{abstract}

Keywords. Ionosphere (Electric fields and currents; Ionosphere-atmosphere interactions; Ionospheremagnetosphere interactions)

Correspondence to: $\mathrm{O}$. Amm

(olaf.amm@fmi.fi)

\section{Introduction}

In this paper, we point out the present status of, and future opportunities for quasi-instantaneous, data-driven, mesoscale, three-dimensional (3-D) ionospheric modelling, and the observations that enable us to do such modelling. Since this type of 3-D ionospheric modelling and related observations is a novel field of research, in addition to providing an overview of the present status of already existing research, a major part of this paper is dedicated to point out how presently existing 2-D modelling techniques and observations can be extended to, and used for, 3-D modelling in the future. For this part of the paper, our main goal is to make the scientific community aware of the exciting new scientific opportunities and challenges in this young field of research.

There are a number of unresolved issues, of key importance to ionospheric physics and ionosphere-magnetosphere coupling, that may only be resolved through 3-D studies. Three examples are given below:

\section{1) The role of ionospheric induction for magnetosphere-} ionosphere coupling

While the largest portion of the large-scale and mesoscale electric fields in the ionosphere can well be approximated as electrostatic, inductive electric fields in the ionosphere, which are caused by rapid local changes of current systems and the magnetic field associated with them, play an important role during the most dynamic situations in the geospace

Published by Copernicus Publications on behalf of the European Geosciences Union. 
environment (Vanhamäki et al., 2007). Such electric fields cause changes in the horizontal and field-aligned currents and therefore in the magnetosphere-ionosphere coupling. These electric field are altitude-dependent. Electric field components parallel to the magnetic field may lead to space charge accumulation. These situations and their interplay can only fully be understood in a truly 3-D description.

\section{2) Current closure within the ionosphere and the Cowling channel}

In a truly 3-D description of the ionosphere, currents cannot only close through the magnetosphere as in the 2-D case, but also via loops extending in the vertical direction inside the ionosphere. Such loops, which can arise from the spatial variability of the ionospheric electric field and the conductances, can be highly important particularly for situations with steep conductance gradients. One example of such a situation is the Cowling channel which is believed to exist in the substorm auroral bulge and to carry a major part of the substorm wedge current (Fujii et al., 1994; Amm et al., 2001; Gjerloev and Hoffman, 2002). The electrodynamics of such a current system can therefore not be fully understood without a 3-D description.

\section{3) Mesoscale thermospheric upwelling}

Recently the CHAMP satellite has observed mesoscale structures in the upper thermosphere in the region of the cusp (Lühr et al., 2004; Schlegel et al., 2005). The heightintegrated conductivities of a 2-D horizontal ionospheric model cannot properly deal with the localised heating, upwelling and consequent modification of the ionosphere that are implied by these observations.

A large part of the observations of the ionosphere traditionally falls into two classes dictated by the type of observation used: In one class, the observations are made along a single, typically vertical or field-aligned line (e.g. with ionosondes or incoherent scatter radars). In this case, often a high spatio-temporal resolution can be achieved along that line of sight, but little can be said about neighbouring plasma regions and gradients perpendicular to that line. The other class of observations is based on magnetometers, which can be distributed as a network in the horizontal direction on the ground. In this case, horizontal ionospheric variations can be measured, but due to the fundamental properties of potential fields, nothing can be said about the vertical structure of the ionosphere. Accordingly, ionospheric modelling concentrates in the first class on one-dimensional modelling, and in the second class on two-dimensional horizontal modelling where the ionosphere is treated as a thin, height-integrated sheet.

In the real ionosphere, however, dynamical temporal variations occur simultaneously in all three spatial directions, par- ticularly under disturbed geomagnetic conditions like substorms, with timescales of some seconds to some $10 \mathrm{~s} \mathrm{min.}$ In order to point out a few major physical effects that cannot be addressed by a conventional 2-D model of the ionosphere consisting of a height-integrated, infinitely thin sheet, let us consider a very simple 3-D model of the ionosphere that consists of two thin current sheets, one at the altitude of the Hall conductivity maximum, and one at the altitude of the Pedersen conductivity maximum. Let us further assume that the two sheets and the magnetosphere are connected by currents flowing along the field lines. Even in this simplest model the following new 3-D effects occur, which are further discussed in Sect. 2:

- Self-induction and mutual induction (variable with height) within the ionosphere

- Current closure via vertical loops inside the ionosphere

- Altitude-dependent contribution of neutral winds to the electric field

- Altitude-dependent contribution of polarisation space charges to the electric field

Further, the effect of current closure on different spatial scales, i.e. smaller-scale current systems closing at higher altitudes than larger-scale ones (e.g. Brekke, 1997), imposes a height dependence of the electric field.

While it may be possible to neglect some of the abovedescribed effects for global modelling in a first-order approach, for mesoscale (scale lengths of some 10s up to some $100 \mathrm{~s} \mathrm{~km}$ ) modelling and on timescales of 10s of seconds, the electrodynamics effects become highly significant, as has most clearly been shown by Vanhamäki et al. (2007). They demonstrate that at some local "hotspots", the currents due to induced electric fields in the ionosphere can be of the same order as the ones driven by the magnetosphere. Such "hotspots" occur during disturbed situations such as in the centre of a westward travelling surge, an omega band, or a pseudobreakup spiral (Amm et al., 2001). Therefore these effects play a significant role in the magnetosphereionosphere-thermosphere coupling and must be included in related modelling efforts. Neutral atmosphere dynamics, on the other hand, typically operate on longer timescales of several minutes to hours, but on similar spatial scales as mentioned above (e.g. Aruliah and Griffin, 2001). The interaction with the neutral atmosphere is thus a crucial component of 3-D ionospheric modelling.

In the near future, new observations and observational techniques increasingly will allow monitoring of a 3-D domain of the ionosphere instantaneously, or almost instantaneously. Some particularly important examples of such new observations are: the ESA Swarm three spacecraft mission (launch date 2010) with orbits in the F-region ionosphere, the EISCAT 3-D project (planned completion 2011), and 
the global high-resolution field-aligned current mission AMPERE (first data 2009 and fully operational 2011). Further, the Advanced Modular Incoherent Scatter Radar (AMISR) situated in Alaska and Northern Canada will have, when fully constructed, 3-D capability. In addition, there are already existing instruments with 3-D capability such as networks of Global Positioning System (GPS) or other radio wave signal receivers, with which the 3-D ionospheric electron density can be derived using tomographic approaches (e.g. Mitchell and Spencer, 2003; Stolle et al., 2006), and all-sky FabryPerot interferometers (FPI; e.g. Conde et al., 1998), which allow measurement of neutral winds and neutral temperatures at different altitudes using multiple optical emission wavelengths.

Modelling is needed in order to understand and interpret these new data sets, and to integrate them with the existing sets of ground-based data, such as magnetometers, coherent scatter radars, and optical instruments. Therefore, it is timely to devise improved models of ionospheric electrodynamics which are capable of incorporating three-dimensional ionospheric observations, and are able to treat related effects which are neglected in thin-sheet models.

Although with respect to modelling, the focus of this paper is on data-driven techniques, we also shortly discuss numerical simulations that can be run on a mesoscale region. Such simulations can help to understand the origin of the observed processes. On the other hand, Global Circulation Models (GCM) such as NCAR-TIECGM (Richmond et al., 1992) or CTIP (Millward et al., 2001) are not subject of this paper. Although these models have 3-D capabilities both in terms of electrodynamic and neutral parameters, due to their global nature they lack the mesoscale resolution that is necessary for the questions discussed in this paper. Further, due to the statistical nature of these models, they also lack the ability to describe specific, dynamic events in a way as detailed as it can be done with instantaneous, combined data sets of the event. However, for the neutral atmosphere part GCMs may be useful to describe the large-scale state of the undisturbed atmosphere, before a dynamical event starts in our mesoscale modelling box.

The structure of the paper is as follows: in the following section, we discuss what are the issues requiring 3-D observations and modelling of the ionosphere. The third section gives an overview of how this can be achieved by existing and upcoming observations of the ionosphere and thermosphere, and of related techniques to analyse those data, which either are already capable of incorporating 3-D measurements or have the potential to be extended to do so. Finally, we present a summary and outlook. It should be emphasized that for each of these sections, we do not intend to present a review of the complete field of research that the section deals with, but we only focus on selected aspects that are of particular importance for 3-D ionospheric modelling and observations.

\section{Selected major open questions requiring 3-D observa- tions and modelling}

A number of major electrodynamic processes such as the evolution and energetics of substorm, the formation of aurora, the production of magnetospheric convection and current systems are subject to (Solar wind-) magnetosphereionosphere-thermosphere (MIT) interactions. Although these processes are also constrained by macroscopic boundary conditions, they are underlain by more fundamental but not yet resolved physical processes such as the generation of electric fields and currents, particle acceleration/heating, energy/momentum transfer between different mediums particularly between perfectly ionised and weakly ionised plasmas. Field-aligned currents (FACs) are the main mechanism for the MIT coupling, but their fundamental characteristics have not yet been fully understood, e.g. even such as how these FACs close in the auroral coupling region where there is a complex system of Hall, Pedersen and FACs. In order to understand these MIT coupling processes, 3-D spatial and time distributions of the relevant physical parameters are required for solving Maxwell and dynamic equations; most of which are intrinsically related to each other in a way shown by Vasyliunas (1970). It is apparent that at present this can be made only by the thorough monitoring of the high latitude ionosphere as a screen of the whole magnetosphere, using insitu and ground-based spatially well-coordinated networks that combine complementary instruments. It is also essential to understand the dynamics of the upper atmosphere particularly down to gravity wave scales and its interaction with the electrodynamics of the ionosphere. The shortcoming in our current understanding is, however, greatly due to observational constraints.

An important new aspect for the detailed understanding of the coupling of current systems is that it is necessary to understand the system not only in terms of DC currents, but also to understand the consequences of the time variations of the system, i.e. the effects of induction and the transport of waves, and how both are interlinked. We limit the discussion in this paper to the inductive effects in the ionosphere-magnetosphere current circuit which are moderated by Alfvén waves, and to the self-induction within the ionosphere.

In this section, we identify five major open questions that are related to AC or DC coupling of the magnetosphere, ionosphere and thermosphere which need 3-D observations and modelling in order to become resolved.

\subsection{What is the 3-D effect of Alfvén waves in M-I cou- pling?}

The ionosphere and magnetosphere are coupled by Birkeland currents that are field-aligned (FACs) closing in the ionosphere and driven by a generator due to the solar wind acting at the magnetopause. In the steady state the ionospheric 
electric field $\boldsymbol{E}$ is simply electrostatically mapped onto the interplanetary $\boldsymbol{E}$ on open magnetic field lines, and onto the magnetospheric convection $\boldsymbol{E}$ on closed ones, respectively. It is assumed that there is no electric field parallel to $\boldsymbol{B}, E_{\|}=0$, due to the very high mobility of electrons in the field-aligned direction. However, normally the situation varies in space and time, in which case the electric fields are not mapping anymore, even for $E_{\|}=0$ everywhere. The electric field has a curl which is directly related to temporal changes in the magnetic structure (e.g. Cowley and Lockwood, 1996; Toivanen et al., 1998; Lotko, 2004). Then the ionosphere is inductively decoupled from the interplanetary space or magnetosphere, respectively. Such cases exist whenever a relatively fast local change of the magnetic structure occurs, as for example in the cases of an Flux Transfer Event (FTE) at the dayside magnetopause or a substorm in the magnetotail. In these situations, the model of an Alfvén wave being transmitted from a generator is thought to be applicable. The first to employ this concept was Scholer (1970) in the context of artificial ion clouds. Here, the term "wave" should be understood as some variation in time and space over scales where Magnetohydrodynamics (MHD) is valid, and it is not restricted to oscillatory changes like pulsations. Simultaneous observations of $\boldsymbol{E}$ in the magnetosphere and ionosphere at locations that map along the background $\boldsymbol{B}$ have been done, and differences from what is expected for electrostatic mapping were attributed to inductive decoupling (Baker et al., 2004). Also MHD simulations show signatures of large scale induction in the M-I coupling system (Ober et al., 2006).

The reflection coefficient of Alfvén waves at the ionosphere expresses the ratio between the incident and reflected electric field amplitude $E_{r}$ and $E_{i}$ (Scholer, 1970):

$\frac{E_{r}}{E_{i}}=\frac{\delta B_{r}}{\delta B_{i}}=\frac{\Sigma_{A}-\Sigma_{P}}{\Sigma_{A}+\Sigma_{P}}$

Here, $\delta B_{r}$ and $\delta B_{i}$ are the magnetic field disturbances due to the incident and reflected wave, respectively, $\Sigma_{P}$ is the height integrated ionospheric Pedersen conductivity, and $\Sigma_{A}=\left(\mu_{0} v_{A}\right)^{-1}$, with $v_{A}$ being the Alfvén velocity, is the wave impedance above the E-Region of the ionosphere. Equation (1) is valid for vertical background $\boldsymbol{B}$ and horizontally uniform conductances, and assuming a 2-D thin sheet ionosphere for which the mentioned height-integrated conductances are applicable. Since typically $\Sigma_{A} \ll \Sigma_{P}$ holds, the electric field just above the E-Region of the ionosphere is relatively weak, and the components from opposite directions of propagation nearly cancel each other. However, after travelling along $\boldsymbol{B}$ by about at least one wavelength, which is typically several thousand kilometres, an impulsive change which is first incident and its reflection from the ionosphere would be seen clearly separated in time by a few tens of seconds, and possibly also separated in space if the plasma is drifting. Observations of electric fields at about $1 R_{E}$ and higher up with considerably larger strengths than normally seen at the ionosphere are thus consistent with wave reflection at the ionosphere (e.g. Aikio et al., 1996).

As outlined above, traditionally the magnetosphereionosphere coupling via Alfvén waves has been described in a framework where the ionospheric conductances are assumed to be uniform, and where the dynamics happen essentially in two dimensions, along $\boldsymbol{B}$ and in one direction perpendicular to $\boldsymbol{B}$, while derivatives in the third direction are assumed to be zero. In addition, a thin sheet ionosphere is assumed. However, in reality 3-D effects can be produced both by the generator mechanism in the magnetosphere, and by the reflection process of the waves at the ionosphere, here particularly due to the effect of strong ionospheric conductance gradients as they are known to exist during the most dynamic situations, as in the cases of a westward travelling surge (WTS) or omega bands analysed by Vanhamäki et al. (2007). Thus a truly 3-D description of the Alfvén wave coupling and their reflection at the ionosphere which replaces Eq. (1) is needed for a full understanding of M-I coupling. Some major steps in this direction have been already been taken: Lysak and Song (2001) developed a 3-D propagation model for Alfvén wave propagation where some initial conditions for the waves at an upper model boundary at several $R_{E}$ altitude, and the ionospheric boundary conditions are given. Lotko (2004) described an iterative approach where a magnetospheric and an ionospheric model can be linked taking into account the inductive effects within the MI-coupling loop. However, both studies still use a thin-sheet ionosphere within which the ionospheric part of the coupling cannot be fully described. An important task for the future will be to link such simulations and general coupling models to actual observations both in the ionosphere and the magnetosphere.

\subsection{What is the effect of self-induction of the ionosphere?}

Magnetosphere-ionosphere coupling via the Alfvén waves is an inductive process. For example, the reflection process described by Eq. (1) is the result of a self-induction process produced by an incident Alfvén wave with an electrostatic (divergent) electric field entering a horizontally uniform ionosphere, and thus generating a purely divergent Pedersen polarisation current. However, self-induction processes can also occur inside the ionosphere for time dependent phenomena. They arise from eddy currents closing inside the ionosphere, which are Hall currents under conditions of horizontally uniform conductivities,. A time varying ionospheric eddy current involves an inductive (rotational) $\boldsymbol{E}$, which in addition to the divergent Pedersen current and rotational Hall currents resulting from the electrostatic $\boldsymbol{E}$, drive divergent Hall and rotational Pedersen currents (Yoshikawa and Itonaga, 1996; Buchert, 1998; Yoshikawa and Itonaga, 2000; Yoshikawa, 2002). Taking ionospheric induction into account makes the system 3-dimensional. Figure 1 shows schematically the Alfvén wave reflection process including 


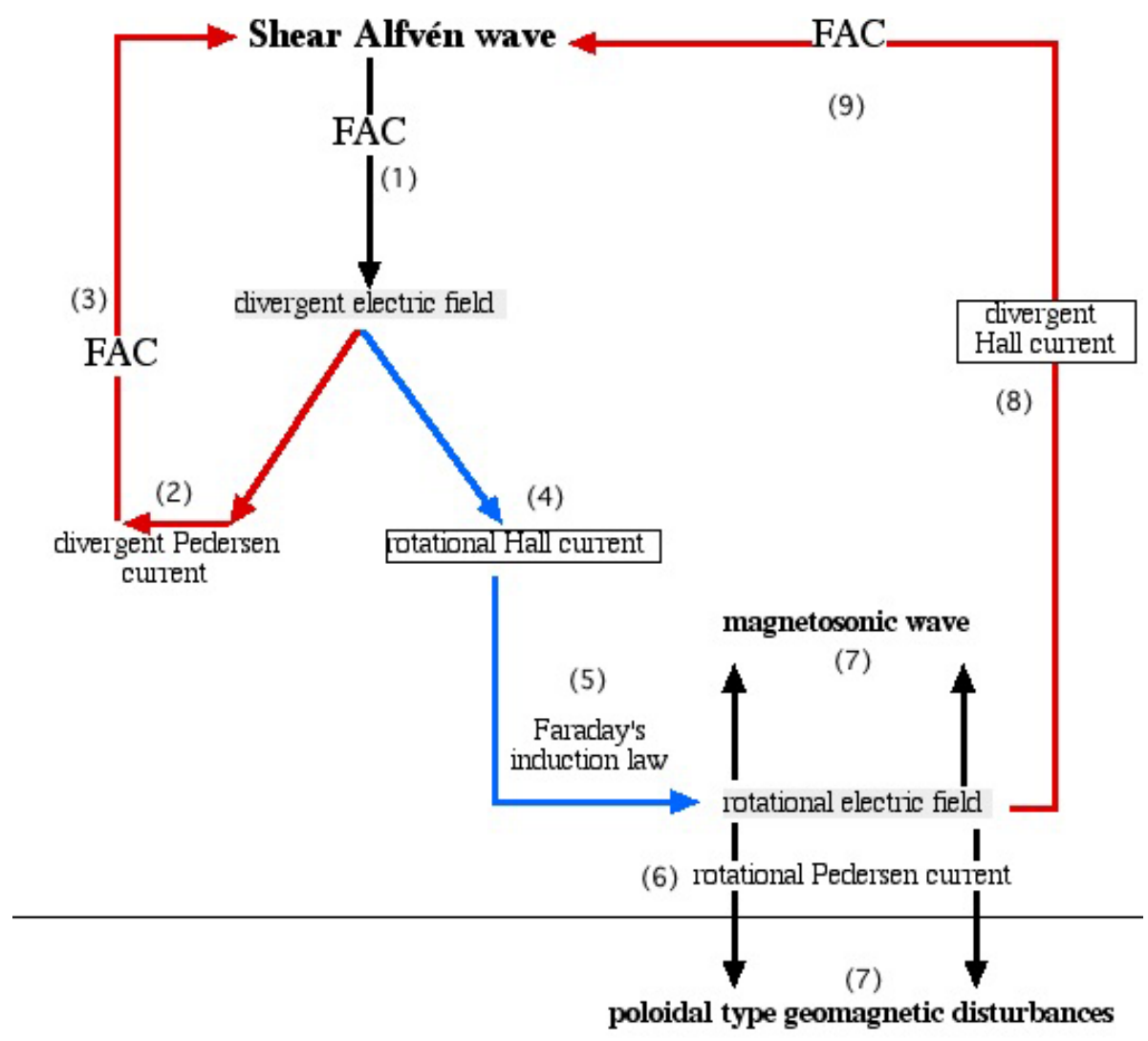

Fig. 1. Flowchart of the Alfvén wave reflection process: (1) incident shear Alfvén wave carries FAC and divergent $\boldsymbol{E}$-field. This $\boldsymbol{E}$-field drives divergent Pedersen current (2) and rotational Hall current (4). In the electrostatic case the reflected Alfvén wave (3) is created to balance the divergence of the Pedersen current and the FAC carried by the incident and reflected waves. When inductive processes are included, an additional rotational electric field is created (5). The rotational electric field is transmitted in the magnetosphere as a fast magnetosonic wave and in the atmosphere as a poloidal type geomagnetic disturbance (7). In the ionosphere it drives rotational Pedersen currents (6) and divergent Hall currents (8). The FAC (9) associated with the divergent Hall current also modifies the reflected shear Alfvén wave (3) (from Fig. 3 of Yoshikawa and Itonaga, 2000, modified).

induction in the ionosphere and its coupling to the evanescent compressional mode and to the poloidal-type geomagnetic disturbances below the ionosphere. Lysak (1999) investigated the coupling between these wave modes in detail using a model based on two-fluid equations and a numerical code solving them. In agreement with the self-induction part of the processes sketched in Fig. 1 (processes 5-8), they found that the ground magnetic signature of $1 \mathrm{~Hz}$ waves is dependent on both the Hall and the Pedersen conductivities in the ionosphere.

Ionospheric self-induction may cause some important modifications on magnetosphere-ionosphere coupling phenomena. In the case of horizontally uniform conductivities, the eddy Hall current and eddy Pedersen currents flow in opposite directions, while the divergent Hall and Pedersen currents flow in the same direction. The cancellation of magnetic flux produced by the eddy Hall and eddy Pedersen current partially shield the poloidal component of geomagnetic fluctuations from the ground (Yoshikawa et al.,
2002; Yoshikawa, 2002). Meanwhile inductive divergent Hall currents generate additional FAC and may cause significant modification of total FAC structure (Buchert and Budnik, 1997). The controlling nature of ionospheric selfinduction on the eigenfrequency and the damping factor of geomagnetic field line oscillation as found by Yoshikawa et al. (1999) is one of the manifestations of a feedback effect of self-induction inside the ionosphere to the magnetosphere.

Clearly, induction becomes the more important the faster changes in time occur, or the higher the frequency is, but for self-induction the spatial area over which the magnetic flux changes is also important. Therefore primarily mesoscale and large-scale phenomena should be affected. For example, consider a mesoscale auroral surge that develops in the expansion phase of substorms. Lühr et al. (1998) reported on inconsistencies in the direction of the electric field between the E- and F-region in front of a westward travelling surge, and attributed them to ionospheric self-induction. However, whether the visual evolution of surges in substorms is really 

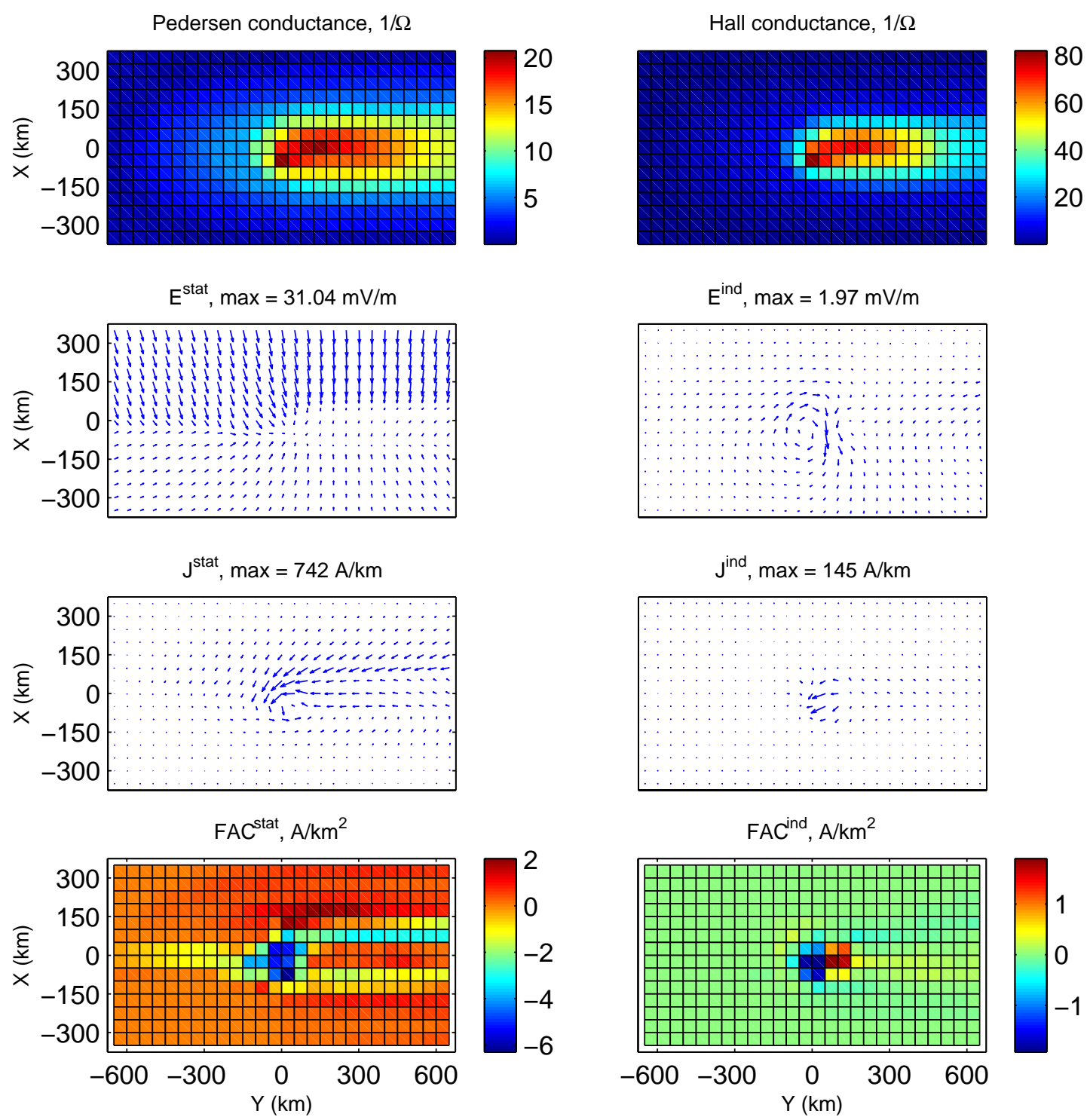

Fig. 2. Static WTS model and induced electric field and currents when the model moves at $10 \mathrm{~km} / \mathrm{s}$ westward. Upper row: Pedersen and Hall conductances; second row: static and induced electric fields; third row: horizontal currents associated with the static and induced electric fields; fourth row: FAC associated with the static and induced electric fields (from Vanhamäki et al., 2007, modified).

influenced by self-induction in the ionosphere, has not been investigated in detail.

Some theoretical support for the hypothesis has been obtained by modelling the evolution of the current systems of some specific ionospheric phenomena including westward travelling surge (WTS) and omega-bands, and using a method based on elementary current systems (see Sect. 3.2.3) for calculating the resulting induced electric fields and currents (Vanhamäki et al., 2007). This is illustrated in Fig. 2. The top row of panels show the Pedersen and Hall conductances, and the middle and lower left panels the electric field $\left(\boldsymbol{E}^{\text {stat }}\right)$ and associated currents $\left(\boldsymbol{J}^{\text {stat }}\right)$ and FAC (FAC $\left.{ }^{\text {stat }}\right)$ of the static WTS model. The middle and lower right panels of
Fig. 2 show the induced rotational electric field $\left(\boldsymbol{E}^{\text {ind }}\right)$ and associated currents $\left(\boldsymbol{J}^{\text {ind }}\right)$ and FAC (FAC $\left.{ }^{\text {ind }}\right)$ that are created when the WTS moves westward at a (high, but not unrealistic) speed of $10 \mathrm{~km} / \mathrm{s}$. The induced electric field is in general very much smaller than the static field, except at a relatively small area around the surge "head", where they are almost equal in magnitude. Also the conductances are enhanced around the surge head, so the small induced electric field can drive relatively large currents $\boldsymbol{J}^{\text {ind }}$. These induced currents are mainly curl-free and concentrated on a small current loop near the surge head, with downwards FAC at the eastern and upwards FAC at the western side. Comparison with the original current system $\boldsymbol{J}^{\text {stat }}$ shows that the induced currents may 
change the ionospheric currents and FAC near the surge head by several ten percents and thus modify the MI-coupling in the WTS. These localised areas in which ionospheric selfinduction is of major importance are termed "hotspots" by Vanhamäki et al. (2007).

Computer simulations, specifically based on Hall-MHD (see Sect. 3.3) that includes the Hall term in the momentum equations which cannot be neglected in the ionosphere, would be a proper tool for the future in order to shed more light on the conditions under which ionospheric self-induction is crucial to understanding magnetosphereionosphere coupling.

2.3 What is the 3-D connection between Hall, Pedersen and field-aligned currents?

In the classic paper by McPherron et al. (1973) the 3-D substorm current wedge was illustrated as a diversion of the cross tail current into the ionosphere where it closes through an auroral electrojet current. Although the substorm current wedge is supposed to be associated with the explosive unloading of energy stored in the magnetosphere, the Hall current itself does not dissipate any energy. Nevertheless, the ionospheric part of the substorm current wedge is commonly referred to as the "unloading component" (e.g. Kamide and Kokubun, 1996). In this simplistic picture the dissipation of energy is due to the meridionally flowing Pedersen currents which are closing east-west aligned FAC sheets (see for example Hoffman et al., 1994; Lui et al., 2003). While the Hall current provides a mean for the cross-tail current to close in the ionosphere through a non-dissipative current loop, it is not clear whether the divergence of the Hall current is fed into FAC's or the overlaying Pedersen currents.

In a steady-state FAC is expressed by

$j_{z}=\Sigma_{P}\left(\nabla_{\perp} \cdot \boldsymbol{E}_{\perp}\right)+\boldsymbol{E}_{\perp}\left(\nabla_{\perp} \Sigma_{P}\right)+(\boldsymbol{b} \times \boldsymbol{E}) \cdot\left(\nabla_{\perp} \Sigma_{H}\right)$

where $\boldsymbol{b}$ is the unit vector along the magnetic field-line, $\Sigma_{P}$ and $\Sigma_{H}$ are the height-integrated Pedersen and Hall conductivities. In reality the total effective electric field $\boldsymbol{E}_{\perp}^{\prime}=\boldsymbol{E}_{\perp}+\boldsymbol{U} \times \boldsymbol{B}$ should be considered, where $\boldsymbol{U}$ is the neutral wind velocity, but the neutral wind velocity is highly height dependent and notoriously difficult to measure; it is also 1-2 orders of magnitude smaller than the plasma velocity in the E-region, and so it is typically set to zero. This assumption allows a useful simplification, which is to use the height-integrated conductivity, which is a parameter that is directly measured by ionosondes and incoherent scatter radars (using model parameters of the neutral atmosphere). The third term on the right side of Eq. (2) corresponds to the divergence of the Hall current. Mathematically, this divergence of the Hall current is not necessarily associated with FACs alone, so it is actually possible to close the auroral electrojets within the ionosphere by setting the left hand term to zero. This raises an intriguing possibility of coupling between the Pedersen and Hall currents, as is the case in a Cowling channel. A Cowling channel consists of a slab of high ionospheric conductances which is bounded to both sides in the direction perpendicular to the channel by very low conducting areas. If at this conductance interface, the currents are prohibited to be carried away from the ionosphere via FAC, a polarisation electric field perpendicular to the channel direction is created. This polarisation electric field then causes secondary currents to flow which cancel the current flow perpendicular to the channel direction, but increase the original currents along the channel direction. The Cowling channel concept plays an important role for the equatorial electrojet where the Earth's magnetic field is approximately horizontal, but it remains to be determined whether it plays a role in the auroral zone where the field is nearly vertical.

In a simplistic case of no neutral wind dynamo, the primary electric field in a Cowling channel is aligned with a channel of enhanced conductance (e.g. an auroral arc) and the Hall current is assumed not to be able to close by FACs but instead builds a polarisation electric field across the arc. Charge will continue to build on the arc boundaries until the polarisation electric field drives a height integrated Pedersen current that exactly cancels the height integrated Hall current. Since the Hall conductivity is peaked around $110 \mathrm{~km}$ high while the Pedersen conductivity is peaked around 120$130 \mathrm{~km}$, these two layers are actually separated in altitude, so these Hall and Pedersen currents and FAC between them make a 3-D current loop. The strength of this polarisation electric field is consequently a function of the Hall to Pedersen conductance ratio and the primary electric field. In this simple geometry it is unclear why the Hall current is not simply connected to the FAC flowing into the magnetosphere. Questions are whether all drainage of the Hall current flow into the magnetosphere completely without accumulating excess charges (and thereby without producing any polarisation electric field), or if some of it is closed via Pedersen currents, accumulating some excess charges and consequently producing a polarisation electric field accordingly (Mallinckrodt, 1985); if the latter is the case, what is the energy source to produce the polarisation electric field and Joule dissipation? And why one or the other mechanism takes place at different times? In order to compute which part of the crosschannel currents are closed through the magnetosphere and which part builds up polarisation charges in the ionosphere, it is necessary to estimate the magnetospheric conductivity perpendicular to $\boldsymbol{B}$ along the respective field lines (e.g. Rostoker and Boström, 1976). Note that it is always possible to define such a conductivity locally if the current density and electric field are known in addition to $\boldsymbol{B}$. These quantities can be estimated using MHD simulations of the magnetosphere, or statistical results from magnetospheric multi-satellite missions like Cluster (Escoubet et al., 2001). 
2.4 What produces polarisation charges and what is the effect on the electric field?

Another interesting issue is how to maintain field-aligned current continuity in depleted electron density regions. This is particularly remarkable in the downward FAC region that is predominantly in the dark ionosphere. Downward FAC pull out ionospheric electrons as the current carriers and deplete the electron density there. If no ionization process takes place, since surrounding electrons cannot approach the depletion region due to their Hall motion, the electron density continues to decrease, resulting in a low conductivity. This depletion may have two requirements, irrespective of the cause, one is that an intense perpendicular electric field is needed to keep the current continuity if the current system is that of a constant current generator. The other is that lack of current carriers should require a field-aligned potential drop somewhere between the ionosphere and the magnetosphere in order to keep the field-aligned current continuity. This is possibly the case in so-called "black aurora" that are occasionally observed by ground-based visible-region all sky imagers. These are characterized by a region of low auroral emissions embedded in regions of, or in the very vicinity of, brighter auroral emissions. Some observations have been made of black aurora that are associated with downward FAC within narrow regions of diverging electric fields (e.g. Marklund et al., 1997), while recent EISCAT observations by Blixt and Kosch (2004) have questioned the presence of FAC in at least one type of black aurora. Understanding the production mechanisms and characteristics of black aurora and their relations to the electrodynamic properties of the ionosphere is an ongoing research topic that clearly requires 3-D observations. In particular, field-aligned measurements are required from not just the E-region, but also through the F-region to the topside ionosphere, and even in the lower magnetosphere.

\subsection{What is the thermospheric contribution?}

The role of the thermosphere is intrinsic throughout this discussion. However, since we assume that the typical reader of this paper might be more familiar with ionospheric electrodynamics and ionosphere-magnetosphere coupling rather than with the neutral atmosphere, in this section the review component of our discussion will be somewhat more pronounced than in other parts of the text.

The thermosphere provides a background composition and sink for dissipation of energy and momentum from the MI coupling process. Subsequently, gravity waves transport momentum and energy in any direction, and over large distances without being confined by magnetic field lines. This is supported by many modelling and observational studies (e.g. Williams et al., 1988). Thermospheric temperatures rise rapidly with altitude up to around $200 \mathrm{~km}$. Above this height the neutral temperature is an isotherm, but there is a strong diurnal, seasonal and solar cycle dependence involving dif- ferences of several hundred Kelvin. In this context it should be remembered that neutral temperatures provide the baseline ambient temperature for the ionosphere, and therefore influence rates of reaction as well as the local ionospheric composition. The thermosphere plays an important role in preconditioning the ionosphere. For this paper three particular qualities of the thermosphere are highlighted that introduce a 3-D behaviour in MIT coupling interactions: the neutral wind dynamo, thermospheric inertia and mesoscale structure.

In terms of mesoscale processes, a largely uninvestigated issue is the contribution of the neutral wind dynamo to the electric field. The neutral wind dynamo refers to the electric field driven by the neutral winds dragging charged particles across magnetic field lines. At E-region altitudes it is considered insignificant compared with the magnetospheric dynamo and it varies with height; for both of these reasons it has usually been ignored in MIT coupling studies. However, Thayer (1998) has used radar derived winds to show that the contribution of the neutral wind dynamo to the effective electric field is significant at all heights, and model simulations show it contributes around 30\% to the global Joule heating rate (Thayer et al., 1995; Lu et al., 1995). During nighttime darkness the E-region disappears as photoionisation no longer replenishes electrons lost through recombination with ions, and so the F-region dynamo becomes dominant. Direct measurements of the neutral wind using satellite-borne and ground-based FPIs have shown that in the F-region the neutral wind dynamo is around $50 \%$ of the magnetospheric dynamo (Killeen et al., 1984; Aruliah et al., 2005).

Thermospheric winds increase rapidly with altitude between $100-200 \mathrm{~km}$ from a few $10 \mathrm{~s} \mathrm{~m} / \mathrm{s}$ to a few hundreds $\mathrm{m} / \mathrm{s}$. By ignoring the neutral wind dynamo it is possible to assume that the electric field at E-Regions is the same as at FRegions. Yet recognition of the neutral wind contribution introduces the requirement for a height-dependent E-field (seen in the frame of reference of the neutral wind, in which Ohm's law in the ionosphere is valid) between these two altitude regions and a height-dependent conductivity.

The inertia of the thermosphere brings in another facet to MIT coupling. The thermosphere is over $99.9 \%$ of the mass of the upper atmosphere and therefore slow to respond indirectly via ion-neutral interactions to magnetospheric forcing. This is the large-scale behaviour observed on scales of thousands of kilometres and hours. The upper thermosphere responds over hours but the lower thermosphere can take days to recover from a storm (Richmond and Lu, 2000). This height dependence will create a vertical shear in neutral wind velocities and frictional heating will be increased. An intriguing aspect of this inertia is the flywheel effect (Lyons et al., 1985), where the neutral wind dynamo can end up driving FAC, particularly in the polar cap (e.g. Thayer et al., 1995; Fujii et al., 2002). This would be exhibited as upward Poynting flux providing feedback to the ionosphere, and has been found in satellite data by Gary et al. (1994). Another 
important consequence of thermospheric inertia is that the redistribution of magnetospheric energy between Joule heating and acceleration of the neutral gas is significantly different when the neutral wind dynamo is included. Thus the ionospheric load depends on the previous levels of geomagnetic activity because the thermosphere integrates the effects of forcing over many hours (Aruliah et al., 1999). This is very much a 3-D response as shown by modelling.

Three-dimensional global circulation models (GCMs) (e.g. Fuller-Rowell and Rees, 1980; Dickinson et al., 1981; Richmond et al., 1992; Millward et al., 2001) and semiempirical models of the thermosphere have been in existence for around 30 years (Hedin et al., 1974). Consequently the large-scale behaviour of the thermosphere is well understood. However, more recent observations reveal that the thermosphere shows a fairly rapid localised response to particle precipitation and electric field variation on mesoscales (i.e. tens of kilometres and tens of minutes). In particular, large vertical winds of up to $100 \mathrm{~m} / \mathrm{s}$, lasting for a few minutes have been observed regularly by ground-based FPIs, caused by localised upwelling due to Joule heating in the auroral regions in both hemispheres (e.g. Smith, 1998; Innis et al., 1999; Aruliah et al., 2005). Also, recent satellite measurements using an accelerometer on the CHAMP satellite have shown unexpected structures in thermospheric density, of the order of hundreds of kilometres in size (Schlegel et al., 2005; Liu et al., 2005) as well as large vertical winds in the cusp region (Lühr et al., 2004). This behaviour will have consequences for the height profile of the ionospheric conductivity via the servo mechanism: which is when the neutral winds as well as electric fields can drive plasma along magnetic field lines to higher or lower altitudes, and establish the F2 peak at a new height according to the balance between diffusion and loss. (e.g. Rishbeth et al., 1978; Hedin et al., 1996).

Mesoscale structures do not appear satisfactorily in current GCMs, largely because the spatial grid sizes are too large. Upgrading to a mesoscale, non-statistical 3-D ionosphere description will require an upgrade in quantity and location of thermospheric observations and increases in spatial grid resolution for GCM's too. Measurements of the uncharged atmosphere are difficult to obtain, but there are several approaches to improvements that are outlined in Sect. 3.1.2 and references therein.

\section{Ionospheric 3-D electrodynamics: observations and methods}

At present, the available measurement devices do not provide simultaneous observation of all the 3-D electrodynamic and plasma parameters for a given domain of time and space in the ionosphere. Therefore, data analysis techniques are needed to derive unobserved ionospheric parameters from observed ones and to infer parameters unobservable in a data void area at a given time from observations in other spatial domains. Corresponding to the topic of this paper, we focus our discussion on techniques which are driven preponderantly by instantaneous observation of the event under question. Since the criteria for data availability are relatively strict, we will mostly consider techniques which are applied to the mesoscale with spatial scale lengths of 10 to hundreds of kilometres, and temporal scale lengths of seconds to tens of minutes. In this section, we will review some selected techniques that fulfill these criteria, and point out their potential for 3-D modelling. In addition, we shortly discuss numerical simulations that can be run in a mesoscale ionospheric domain, and which may shed more light on the origin of the observed structures.

Electromagnetic data analysis techniques take electric and/or magnetic fields, horizontal and/or field-aligned currents, and ionospheric conductivities or conductances (height-integrated conductivities) as input or output parameters. Table 1 summarizes selected techniques in terms of input and output electromagnetic variables, as well as underlying assumptions upon which these different techniques are built. For several of the techniques presented, the knowledge of ionospheric conductance distributions, or for 3-D applications height resolved ionospheric conductivity distributions, is a crucial prerequisite. Therefore, in order to obtain reliable conductivity estimates for these techniques, the 3-D imaging of ionospheric electron density (e.g. with the tomographic techniques described in Sect. 3.2.2) is vital prior to 3-D modelling of ionospheric electromagnetic variables.

We will first give a short overview of observations that are presently available for 3-D ionospheric modelling. Secondly, we will discuss selected data analysis techniques, organized with respect to present and/or potential future 3-D capability and introduce the importance of first principle models to fulfill the understanding of observed processes. Following a short discussion about numerical simulations, we close this section with the description of upcoming instrumentation of particular relevance.

\subsection{Observations}

An overview of selected types of instrumentation for electromagnetic and neutral observations is given in Fig. 3a (Northern Hemisphere view) and $3 b$ (Fennoscandian region). The parameters measured by these instruments and methods in which they are employed are given in Table 2. The figures reveal large regions without a comprehensive combination of different data types. Relatively dense networks are provided above Europe and North America.

It is indispensable to have a well-coordinated observing network with sufficient spacing that is adequate to appropriately address each of physical processes concerned. 
Table 1. The electromagnetic techniques described in Sect. 3.2.1 are summarized in terms of the input and output parameters, and the assumptions required to apply these techniques to the analysis of those electromagnetic parameters. Further, the questions (corresponding to the sections of Sect. 2) which a 3-D version of the techniques can address are marked, and what additional development is needed for such a 3-D version.

\begin{tabular}{|c|c|c|c|c|c|c|}
\hline Input & Assumption(s) & Output & Name of technique & Remarks & $\begin{array}{l}\text { 3-D version } \\
\text { can address } \\
\text { question of } \\
\text { Sect. } 2\end{array}$ & $\begin{array}{l}\text { with additional input } \\
\text { of }\end{array}$ \\
\hline \multicolumn{7}{|c|}{ - Data-based analysis techniques: } \\
\hline $\boldsymbol{B}_{G}$ & $\Sigma_{H}, \Sigma_{P}$ & 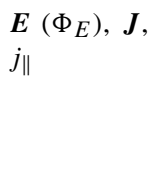 & KRM & $\begin{array}{l}\text { forward method; } \\
\text { use CECS-based } \\
\text { version if applied } \\
\text { regionally }\end{array}$ & $\begin{array}{l}3 \\
5\end{array}$ & $\begin{array}{l}\text { equipotential static } \boldsymbol{E} \\
\text { field assumption along } \\
\boldsymbol{B}_{\text {earth }} \\
\text { comparison with F- } \\
\text { layer } \boldsymbol{E} \text { field }\end{array}$ \\
\hline $\begin{array}{l}\boldsymbol{B}_{G}, \\
\left\{\boldsymbol{E}\left(\Phi_{E}\right), \text { satellite }\right. \\
\text { data }\}\end{array}$ & $\Sigma_{H}, \Sigma_{P}$ & $\begin{array}{l}\left\{\boldsymbol{E}\left(\Phi_{E}\right)\right\} \\
\boldsymbol{J}, j_{\|}\end{array}$ & AMIE & $\begin{array}{l}\text { optimisation tech- } \\
\text { nique; data need } \\
\text { not to cover whole } \\
\text { analysis area }\end{array}$ & $\begin{array}{l}1,3 \\
5\end{array}$ & $\begin{array}{l}\text { regional SECS-based } \\
\text { version with } 2 \text { layers } \\
\text { and induction effects } \\
\text { included } \\
\text { integration with re- } \\
\text { gional neutral atmo- } \\
\text { sphere model }\end{array}$ \\
\hline------- & $\alpha=\Sigma_{H} / \Sigma_{P}$ & $\begin{array}{l}\Sigma_{H}, \Sigma_{P} \\
J, j_{\|}\end{array}$ & $\begin{array}{l}\text { method of character- } \\
\text { istics (MoC): } \\
\text { "JEQ-based" } \\
--------\end{array}$ & $\begin{array}{l}\text { forward method; } \\
\alpha \text { assessible from } \\
\text { ASC data or } \boldsymbol{B}_{G}\end{array}$ & $\begin{array}{l}1,3 \\
5\end{array}$ & $\begin{array}{l}\boldsymbol{E} \text { and } \boldsymbol{B} \text { from fleet of } \\
\text { satellites; } \\
\text { multi-layers; } \\
\text { integration with re- } \\
\text { gional neutral atmo- } \\
\text { sphere model }\end{array}$ \\
\hline$j_{\|}, \boldsymbol{E}$ & & & "FAC-based" & & & \\
\hline \multicolumn{7}{|c|}{ - Simulation-based techniques: } \\
\hline $\begin{array}{l}\text { boundary conditions } \\
\text { at magnetopause } \\
\text { and inner magne- } \\
\text { tospheric modeling } \\
\text { boundary }\end{array}$ & $\begin{array}{l}\text { validity of MHD; } \\
\text { static mapping } \\
\text { from and to } \\
\text { ionosphere }\end{array}$ & $\begin{array}{l}\Sigma_{H}, \Sigma_{P}, \boldsymbol{J} \\
j_{\|}, \boldsymbol{E}\end{array}$ & $\begin{array}{l}\text { global (standard-) } \\
\text { MHD simulation }\end{array}$ & $\begin{array}{l}\text { chain of causes and } \\
\text { consequences can be }\end{array}$ & 2,3 & $\begin{array}{l}\text { SECS-based iono- } \\
\text { spheric solver in- } \\
\text { cluding induction } \\
\text { effects }\end{array}$ \\
\hline $\begin{array}{l}\text { boundary conditions } \\
\text { at magnetopause and } \\
\text { ionosphere }\end{array}$ & $\begin{array}{l}\text { validity of MHD; } \\
\text { validity of integra- } \\
\text { tions as listed in } \\
\text { rightmost column }\end{array}$ & $\begin{array}{l}\Sigma_{H}, \Sigma_{P}, \boldsymbol{J} \\
j_{\|}, \boldsymbol{E}, \boldsymbol{U}\end{array}$ & Hall MHD & $\begin{array}{l}\text { clearly analysed; } \\
\text { difficult to integrate } \\
\text { with observations }\end{array}$ & $1,2,3,5$ & $\begin{array}{l}\text { integration of plasma- } \\
\text { neutral interaction; } \\
\text { integration of plasma } \\
\text { source and loss terms; } \\
\text { integration of basic } \\
\text { thermospheric chem- } \\
\text { istry }\end{array}$ \\
\hline
\end{tabular}

\subsubsection{Electromagnetic variables}

Among the measurement types listed in Table 2, incoherent scatter (IS) radars provide profiles of charge density, temperatures, and electric field, and thus are one of the most powerful ground-based instruments. However, presently most of the IS radars provide these information only along a single line of sight. New phased array beam generation techniques may improve the situation. An increasing worldwide network of coherent scatter radars, many of which are part of the SuperDARN project (Greenwald et al., 1995), provides ionospheric electric field data. Magnetic observations from ground based instruments provide essential information in 2-D on the ionospheric current system. Arrays of magnetometers like, e.g. the MIRACLE network in Fennoscandia, also provide the advantage of dense regional coverage. The global 2-D distributions of Birkeland currents at the topside ionosphere can be derived from magnetic field data of the Iridium satellite constellation (Anderson et al., 2002). Perspectives on how some instrument types will be extended for 3-D observations and which new facilities are expected to complete the 3-D capability is discussed in Sect. 3.4. 
Table 2. Electromagnetic and neutral variables relevant to 3-D ionospheric modelling are listed along with the observation facilities and the methods that can utilize them (MoC: method of characteristics). Italic writing gives upcoming instrumentation.

\begin{tabular}{lll}
\hline Observation & Instruments & Data analysis techniques \\
\hline $\boldsymbol{E}$ & - SuperDARN HF radars (regional) & AMIE, MoC \\
& - IS radars (local, 1-D height resolved profiles) & AMIE, MoC \\
& - STARE VHF radars (regional, until 2005) & AMIE, MoC \\
& - VHF radar with simultaneous observation at different altitudes (regional) & AMIE, MoC \\
& - EISCAT 3-D/AMISR (regional, $\sim 50^{3} \mathrm{~km}^{3}$ ) & AMIE, MoC \\
& - Swarm satellites (globally available for local 3-D) & MoC \\
\hline $\boldsymbol{B}$ & & AMIE,MoC,KRM \\
& - Ground based magnetometers (regional) & AMIE, MoC \\
& - Iridium and AMPERE satellites $($ global, 2-D) & MoC \\
\hline$T_{e}, T_{i}$ & - Swarm satellites (globally available for local 3-D) & \\
\hline $\boldsymbol{U}, T_{n}$ & - IS radars (local, 1-D height resolved profiles) & 3-D tomography \\
\hline$n_{e}$ & - Swarm satellites (globally available for local 3-D) & 3-D tomography \\
\hline auroral emission & - FPI (local) & all-sky cameras (regional, particularly networks like THEMIS, ALIS) \\
\hline
\end{tabular}

\subsubsection{Neutral density and winds}

The neutral component of the upper atmosphere is a more difficult medium to sample and measure than the ionised component; for the most part, too high for rockets and balloons, too low for satellites. Low orbiting satellites provide in-situ density, composition, wind and temperature measurements (e.g. Spencer et al., 1981; Shepherd et al., 1993; Liu et al., 2005). The global coverage is vital for observing largescale phenomena such as tides which are responsible for horizontal and vertical transport of energy and momentum.

Passive observations of auroral and airglow emissions are a very important source of thermospheric observations of neutral winds and neutral temperatures. The intensities give an indication of the composition. These are provided by photometers, all-sky imagers, Fabry-Perot and Michelson Interferometers and spectrometers. The most commonly used emissions for the mesosphere and lower thermosphere altitude region at $80-100 \mathrm{~km}$ are OI $(557.7 \mathrm{~nm}), \mathrm{Na}(589.2 \mathrm{~nm})$ and the near infra-red $\mathrm{OH}$ night-glow (e.g. Taylor et al., 1987), and for the upper thermosphere at around $240 \mathrm{~km}$ it is OI $(630.0 \mathrm{~nm})$ (e.g. Biondi et al., 1999).

Height profiles of emission intensities have been obtained from a small number of satellite limb-scanning observations, rocket campaigns and chemical modelling (e.g. Kurihara and Oyama, 2005). Height profiles are also obtained from active sampling, through Rayleigh, Mie and Raman scattering of laser light by the upper atmosphere, by lidars, both ground-based and on satellites (e.g. Gardner, 2004). Ground- based lidar observations are limited to a maximum altitude of $120 \mathrm{~km}$. The lower thermosphere $(90-150 \mathrm{~km})$ has been measured indirectly by meteor echoes observed by radars, MF radar (e.g. Kishore et al., 2002; Manson et al., 1985) and incoherent scatter radar (e.g. Kirkwood, 1996).

2-D horizontal maps of winds and temperatures for a given height region can be obtained from networks of optical instruments, such as the Scandinavian all-sky cameras that comprise the Auroral Large Imaging System (ALIS) network (e.g. Aso et al., 2000), FPI networks with overlapping fieldsof-view (e.g. Aruliah et al., 2005) and from all-sky Scanning Doppler Imagers (Conde and Smith, 1998). Observations from multiple heights using different emissions and overlapping fields-of-view from several instruments allow a 3-D capability. The ALIS network also provides 3-D tomographic imaging of auroral emissions (e.g. Gustavsson et al., 2001).

\subsection{Data analysis techniques}

\subsubsection{Electrodynamic data analysis techniques and their potential for extension to $3-\mathrm{D}$}

In this section, we give a short overview of the electrodynamic data analysis techniques presented in Table 1 . The aim of these techniques is to derive a full set of ionospheric electrodynamic parameters (conductances, electric field, horizontal and field-aligned currents) from different sets of observed parameters. In their present form, all these techniques are designed for application to 2-D problems, where 



Fig. 3. (a) Northern Hemisphere map of selected observing network of ionospheric and thermospheric variables relevant for the electrodynamics of the 3-D high-latitude ionosphere. (b) Detailed view of the observation network in the Fennoscandian region.

all variables may vary in both horizontal directions, but are integrated over the vertical direction. We will discuss the potential future extension of these techniques to 3-D heightresolved applications. In the last columns of Table 1 we also state which of the science topics discussed in Sect. 2 can be addressed by applying these extended 3-D techniques, and what additional requirements are needed to achieve the 3-D capability.

\section{Overview of data analysis techniques}

The method of characteristics is a technique that infers spatial distributions of the macroscopic parameters of ionospheric electrodynamics in a forward manner, by combining two possible sets of ground-based or space-based input data: The "JEQ-based" version of the method (Inhester et al, 1992; Amm, 1995, 1998) combines measurement of the ground magnetic field disturbance, from which the ionospheric equivalent currents can be calculated by upward field continuation (Amm and Viljanen, 1999), with the iono- spheric electric field observed, e.g. by coherent scatter radars. In contrast to the methods described below, only the Hall to Pedersen conductance ratio $\alpha$ needs to be assumed in order to calculate the Hall conductance distribution as a primary output. The name of the method refers to that it is based on solving a first-order partial differential equation for the Hall conductance along the characteristics of that equation (e.g. Courant and Hilbert, 1962). Subsequently, the Pedersen conductance distribution and FAC are inferred. This technique is typically applied to a meso-scale region. The "FAC-based" version of the method of characteristics has been introduced by Amm (2002), in which the ground magnetic field input is replaced by an input of FAC measured by a fleet of satellites. The mathematics of this version is very similar to the "JEQ-based" version.

The KRM (Kamide-Richmond-Matsushita) method (Kamide et al., 1981) estimates the 2-D horizontal and FAC current system in the polar ionosphere from the ground magnetic field, using assumed or observed ionospheric conductance distributions. For reliable results, it is important 
to use observed conductances, as they can for example be estimated from the tomographic techniques described in Sect. 3.2.2. KRM assumes an electrostatic electric field, and the Ohm's law, ignoring neutral wind contributions to the ionospheric current. The core part of KRM is an iteration scheme to solve the equation of Ohm's law for the electric potential. Other ionospheric parameters can be calculated from the obtained electric potential and the input conductance. The KRM method is originally designed for global-scale analysis, and when using the original scheme in a regional analysis, the influence of unknown boundary conditions becomes critical (Murison et al., 1985). However, it is possible to use, e.g. AMIE (see below) electric potential results as boundary conditions required for the regional KRM. Further, a new technique that has the same input and output parameters as KRM, but is based on cartesian elementary systems (CECS; Amm, 1997) has been developed by Vanhamäki and Amm (2007). This technique does not require explicit boundary conditions and has been shown to be applicable for regional analysis.

The Assimilative Mapping of Ionospheric Electrodynamics (AMIE) procedure, developed by Richmond and Kamide (1988), carries out an objective multivariate functional analysis of high-latitude ionospheric electrodynamic variables: irrotational electric fields (electrostatic potential), ionospheric currents, and magnetic field perturbations, with all the variables presumed being related linearly under the assumption that the ionospheric conductance is known and that neutral wind effects are negligible. These are the same set of assumptions as used in the KRM technique. On the other hand, AMIE is a data assimilation procedure, essentially based on Optimal Interpolation (OI) theory (e.g. Matsuo et al., 2005), that is capable of assimilating any of the electrodynamic variables into a model of the electric potential. AMIE is originally designed for global-scale analysis, and uses modified spherical harmonic functions as a basis. One way to build regional analysis methods is to consider compactly supported functions such as radial functions.

\section{Potential extension of the techniques to 3-D}

There are two major paths along which the described electromagnetic data analysis techniques can be extended for 3-D application: First, if the height profile of the ionospheric conductivities is known as a function of horizontal position, and the electric field is assumed to be independent of height, all three methods mentioned can be straightforwardly extended to a 3-D case without major changes in the analysis procedure. This option requires the knowledge of the altitude dependence of the conductances on a horizontal region, as it can be derived e.g. by the tomographic techniques mentioned in Sect. 3.2.2, or using the upcoming EISCAT 3-D or AMISR radars. However, due to the assumption of an altitude-independent electric field, several of the 3-D effects mentioned in the introduction will not be included in the analysis results.

The second path relies on additional observed input data other than the height profiles of ionospheric conductances, which will be different for each technique: For the method of characteristics, if a fleet of satellites at different ionospheric heights observes the magnetic field disturbance, it is possible to derive the vertical component of the curl of the integrated ionospheric currents in the three different layers: one layer extends from the lower edge of the ionosphere to the lower satellite orbit, the second between the orbits of the lower and the upper satellite, and the third from the upper satellite orbit to the upper edge of the ionosphere. Together with electric field measurements and the necessary $\alpha$ assumption, the method of characteristics can now be applied to each of those layers to yield altitude distributions of the ionospheric electrodynamic parameters. For KRM-type techniques, as they estimate the E-region electric field, an immediate 3-D application would be the comparison of its results with F-region electric fields as measured by SuperDARN radars. It is anticipated that there will be differences between both electric field estimates (seen in the frame of reference of the neutral wind) at different heights, due to the contribution of neutral winds and polarisation charges to the electric field. In order to study these contributions by evaluating the electric field differences with altitude, it is however necessary that both electric field estimates are made with the best possible accuracy, i.e. for KRM-type techniques the ionospheric conductances need to be observed, and for SuperDARN there needs to be a good coverage of actual F-region radar backscatter. For AMIE, as it is able to include a multitude of different data sets into its assimilation procedure, eventually it is ideal to assimilate observations of height-resolved neutral winds and ionospheric conductivities together with electric and magnetic field observations into a comprehensive 3-D data assimilation system. In order to keep the inversion well-defined in such a case, clearly a substantial input of 3-D observations, e.g. from tomographic techniques, EISCAT 3-D, or satellite fleets like Swarm, will be needed.

\subsubsection{3-D ionospheric and auroral tomography}

The imaging of 3-D electron density fields has been developed since the late 1990s based on L-band radio wave signals from GPS which are globally available at any time. GPS signals are received at the ground (see Fig. 3) with one receiver seeing up to 8 satellites simultaneously. An appropriate processing of the phase delay of the GPS signal which has crossed the ionospheric plasma allows the determination of the line-of-sight Total Electron Content (TEC). TEC is the integrated measure of the electron density along the radio wave ray path. An ensemble of spatially distributed TEC measurements can be inverted through tomographic techniques to image the 3-D distribution of the electron density in the observed area (e.g. Mitchell and Spencer, 2003; Stolle et al., 
2006). The spatial resolution of such semi-global electron density maps reaches $2.5^{\circ}$ in latitude, $5^{\circ}$ in longitude and about $30 \mathrm{~km}$ in height. The 3-D ionosphere can be imaged with a time resolution of $30 \mathrm{~s}$ in principle.

A crucial challenge in ionospheric tomography is the specification of the vertical electron density distribution since the geometry is poor due to the high elevation of GPS rays. This lack of information needs to be compensated by imposing additional constraints about the vertical profile of electron density from ionospheric models, ionosondes, or radars. A novel possibility arises from GPS radio occultations onboard lowEarth orbiting scientific satellites $(300 \mathrm{~km}-700 \mathrm{~km})$, such as CHAMP or the fleet of the 6 COSMIC/FORMOSAT- 3 satellites. By that a few hundreds of occultations are available globally per day. Occultation rays are almost horizontal, and therefore each single ray contains low information about the horizontal structure of the ionosphere. However, one complete occultation event tells about the vertical structure. In combination with a good coverage of the vertically directed GPS rays received at the ground, they build an excellent opportunity for 3-D reconstruction (e.g. Yin and Mitchell, 2005). GPS occultation are also used to retrieve vertical profiles of electron density (Jakowski et al., 2007) which have been shown to be in reasonable agreement with radar observations (Stolle et al., 2004). They provide further data to be applied in localised tomography.

The main issue in providing reasonable results also in mesoscale electron density imaging is an adequate density of observations which is not necessarily given in most regions. Recently, Lee et al. (2007) presented a localised 3-D ionospheric tomography based on GPS ground receiver readings of the relatively dense GPS receiver network in California around the San Andreas Fault. They emphasized that not only the number but also the distribution of ground receivers is crucial for reliable inversion results. Their technique is free of supporting models of the ionosphere except for the assumption of Chapman layers as the describing function for vertical plasma distribution. These tomographic results obtained a spatial resolution between 75 to $95 \mathrm{~km}$ in horizontal length and $30 \mathrm{~km}$ in altitude.

In order to support 3-D mesoscale electrodynamic modelling, the knowledge of the electron density distribution contributes most to regions equipped with other important ionospheric and thermospheric measurement facilities. Presently, a few such constellations exist, e.g. across Scandinavia (see Fig. 3b). Furthermore, TEC observations such as obtained from signals of the American Navy Ionospheric Monitoring System (NIMS) and the Russian Tsykada satellites, and electron density readings from ionosondes, IS radars and on board low Earth orbiting satellites are ideal candidates for the general enhancement of the electron density distribution observation network.

Tomographic inversion techniques are also used in describing optical auroral emissions (see Sect. 3.1.2). Due to the availability of the optical observations only during dark hours, such analyses are provided for night time. The first 3D imaging has been done with ALIS data (e.g. Nygrén et al., 1998; Gustavsson et al., 2001) and by multi-spectral imaging from a single all-sky imager (Semeter et al., 2001). Soon auroral emission tomography will also be available using the THEMIS network of all-sky imagers.

By using data from distributed incoherent scatter receivers and combining them with tomographic or interferometric techniques, it is possible to obtain 3-D information about small-scale auroral features (e.g. Grydeland et al., 2005; Sullivan et al., 2006). This analysis type uses the ability of an incoherent scatter radar to measure electron density, temperatures and bulk velocities at variable positions along the one-dimensional radar beam, and then combines the data from several of such beams. A disadvantage of almost all presently existing incoherent scatter radar facilities is that the beams are formed by hardware, with heavy antenna dishes that move slowly. This severely limits the spatial coverage or the temporal resolution of the measurements. As two exceptions, the US-built AMISR (Advanced Modular Incoherent Scatter Radar; Nicolls and Heinselman, 2007) and the upcoming EISCAT 3-D incoherent scatter radars form the receiver beams (AMISR), or the transmitter and receiver beams (EISCAT 3-D), by software, thus allowing for a new level of 3-D observations of the ionosphere with incoherent scatter radars.

\subsubsection{Modelling induction with elementary current systems}

The reflection of Alfvén waves can be treated relatively simply only when the conductances $\Sigma_{P}, \Sigma_{H}$, and $\Sigma_{A}$ are assumed to be horizontally uniform. However, this is often a quite unrealistic assumption, particularly for periods of active aurora and substorms. Glassmeier (1983) proposed a theoretical model to describe the influence of horizontally non-uniform conductance distributions on Alfvén wave reflection (neglecting ionospheric induction).

Elementary current systems provide a way to separate mathematically the current system extending from the ionosphere into space from the one closing in the ionosphere for non-uniform conductances. Vanhamäki et al. $(2006,2007)$ described a way to solve the ionospheric induction problem using so called Cartesian Elementary Systems (CECS). This calculation scheme is essentially a finite element method for the curl and divergence of the ionospheric electric field, where CECS are used to represent the curl and divergence of the electric field and currents in one grid cell. This formulation clearly shows how the induced electric field depends on the time-derivate of the divergence-free currents. In the method the potential part of the ionospheric electric field together with the Hall and Pedersen conductances are assumed to be known as functions of time and position. The calculation method then gives the rotational part of the electric field that is induced by the temporal changes. 
The calculation method developed by Vanhamäki et al. (2006, 2007) uses the thin-sheet approximation, so that the ionosphere is handled as a 2-D sheet. One possible way to study induction effects in 3-D ionosphere would be to include a second thin sheet in the model. The two sheets would be separated by $10-30 \mathrm{~km}$ in altitude, so that the upper sheet would contain mostly Pedersen current and the lower mostly Hall current. This model would thus not be fully 3-D, but it would include effects like closed vertical current loops within the ionosphere and inductive coupling between the current sheets. This way we could get some indications about the differences between 2-D and 3-D induction phenomena.

The electric field or the plasma flow above the ionosphere is assumed to be known when using the CECS induction calculation approach. However, the often significantly inductive response of the ionosphere feeds back to the magnetosphere, changing the plasma flow and $\boldsymbol{E}_{\perp}$. Hence, a selfconsistent treatment of electrodynamic processes in the coupled magnetosphere-ionosphere system, as envisaged by Vasyliunas (1970), cannot be achieved with this method alone.

\subsection{Hall-MHD and simulations}

A more holistic approach is a simulation based on the MHD concept for both the nearly collisionless space as well as for the collisional ionosphere. In MHD three basic equations describe the evolution of the variables $\rho, \boldsymbol{v}$, and $\boldsymbol{B}$ in space and time given suitable boundary and initial conditions. In order to describe variations that have small scales in space or are rapid in time, MHD needs to be replaced by the socalled Hall-MHD. With modifications MHD is also a suitable concept for the ionosphere.

The following modifications are important in this respect: In the ionosphere, a partially ionised plasma, the Hall effect must be taken into account always, not only for small scales, therefore Hall-MHD is always the starting point. Neutrals are a significant source or sink of momentum, and a corresponding term must be added in the equation of motion for the plasma, even for zero or constant neutral wind. Finally, ionization and recombination are sources and losses of plasma, and must be considered in the continuity equation. These points were made by Dreher (1997), who presented the basic Hall-MHD equations for a partially ionised plasma, re-derived from them the ionospheric Ohm's law, and performed a 2-dimensional simulation of the coupling between ionosphere and magnetosphere for a simple scenario. The simulation showed that significant transport of plasma occurs when field-aligned currents are closed in the E-Region by Pedersen currents. The electron density gets drained below the background values, and therewith also the conductivities. This effect becomes more pronounced the smaller the spatial scales. Kataoka (2001) improved the simulation by using more realistic ionospheric background conditions than Dreher (1997). Zhu et al. (2001) included thermodynamic ef- fects and showed that also the electron and ion temperatures change considerably.

Hall-MHD equations in principle describe the system completely including induction effects. The simulations cited above addressed rather the dynamic interaction between the ionosphere and magnetosphere by Alfvén waves. The results were confirming the scenario of Alfvén waves described here in Sect. 2.1. No effects were seen that could possibly be related to ionospheric self-induction. However, we expect that such effects would be seen in height-resolved 3dimensional MHD simulations of large scale (thousand kilometre and more) systems. For problems of dynamic or/and three-dimensional character the MHD concept has the potential to result in improved understanding and modelling of the ionosphere and its interaction with space.

Observations have shown that even within the E-Region the neutral wind is not constant over height (e.g. Fujii et al., 1998, Thayer, 1998). For this situation it is likely that strong currents close within the ionosphere at different heights. MHD simulations can take into account a specified time varying and altitude dependent neutral wind. On the other hand, in mesoscale simulations of atmospheric dynamics the instantaneous ionospheric electric field needs to be specified. For example, for an auroral omega band event studied by Amm et al. (2005), the ambient ionospheric electric field and conductance distribution caused a total power of the Joule heating of $\sim 10 \mathrm{GW}$ in an area of $\sim(400 \mathrm{~km})^{2}$ that included the auroral form. This corresponds to the peak power consumption of whole Finland under extreme winter condition, or to the power of several nuclear power plants. The release of such an amount of power on a mesoscale area is clearly expected to affect the neutral atmosphere, but present models cannot tell how. Thus, for a fully self-consistent treatment of the MIT system, the two types of simulations, MHD and thermosphere dynamics, need to be coupled together. This is a complicated task, that has not been endeavoured yet.

\subsection{Perspectives in instrumental development}

As it has become obvious from the discussion in this chapter, the present observing network limits the resolution of 3-D data-driven, instantaneous ionospheric modelling, but both techniques and observational capabilities are moving towards such modelling. To conclude the chapter, we briefly report on major instrument developments that will further lead us to obtain a more comprehensive 3-D data-driven modelling capability.

In terms of electrodynamic observations three types of instruments are expected to greatly improve the 3-D ionospheric modelling capabilities: First, proposals for a set of ionospheric IS radars are ongoing that will measure the electric field at different altitudes in the ionosphere simultaneously. These are the next generation radars "EISCAT 3-D" and "AMISR". The 3-D capability is achieved by using arrays of antennas to form multiple beams by software phasing. 
Secondly, The European Space Agency (ESA) heads and supports the multi-satellite mission Swarm with expected launch in 2010. It will consist of three near-polar orbiting satellites (with initial orbit altitudes of $450 \mathrm{~km}$ of two and $550 \mathrm{~km}$ of the third spacecraft). Each of these satellites provide in situ measurements of the geomagnetic field, the electric field, the ion density, the electron temperature, the ion drift, and neutral density and winds. The great advances in the determination of ionospheric current systems employing the Swarm constellation over single-satellite approaches was demonstrated by Ritter and Lühr (2006). Third, the AMPERE mission consists of more than 70 satellites at $780 \mathrm{~km}$ altitude on circular near-polar orbits, evenly distributed among six equally spaced orbit planes. This will provide a new global Birkeland current distribution with $1^{\circ}$ latitude resolution every nine minutes. Hence the results of this satellite network will also be of significant importance for mesoscale modelling.

The combination of those new instrument types with the existing ones will enable the scientific community to explore full 3-D data-driven, instantaneous ionospheric modelling, and thus take our understanding of the ionosphere and its coupling to the magnetosphere and the thermosphere to a new level.

\section{Summary and outlook}

The ionosphere has long been treated as a 2-D thin layer and often regarded as the bottom boundary condition of the M-I coupling. In addition to the inaccuracies that this assumption imposes on the understanding of ionospheric electrodynamics, it also makes it difficult to model the coupling of the electrodynamics with the neutral atmosphere. This paper aims at emphasizing the importance of 3-D ionospheric modelling for understanding (Solar-) M-I-T coupling processes, the ionosphere itself and major mesoscale processes occurring there, and that the 3-D consideration is indispensable even to determine merely the ionospheric boundary condition for magnetosphere-ionosphere coupling correctly.

A relatively fast change of a magnetic structure produces a rotational electric field that makes the ionosphere inductively decoupled from the magnetosphere, where the 3-D effect of Alfvén waves produced in both the magnetosphere and the ionosphere plays an essential role. The self-induction effect of the ionosphere produces induced currents, which contribute significantly to phenomena in a relatively small area such as the substorm surge head. It should be noted that this induction process is also important for DC type M-I-T coupling as described in Sect. 2.2 and shown in Fig. 2.

Current closure may occur vertically inside the inhomogeneous ionosphere, where the Hall and Pedersen currents and FACs are connected to each other through excess charge accumulation that produces a polarisation electric field. This is a basic process, typically seen in the Cowling channel, but is not yet understood in the M-I-T coupling. The active role of the ionosphere on the M-I coupling has recently drawn attention. The requirement of the current continuity of the ionospheric closure current and FAC may produce intense perpendicular parallel electric fields particularly in downward FAC of the dark ionosphere, due to greatly lowered conductivities and presumably lack of current carriers along FAC. The comprehensive understandings cannot be done without knowing their 3-D characteristics.

As for thermosphere-ionosphere coupling and thermosphere-middle atmosphere coupling, 3-D observations are crucial to understand the thermosphere itself and the coupling with the ionosphere. The effect of the neutral wind dynamo often cannot be neglected in comparison with the electric field imposed by the magnetosphere. The inertia of the thermosphere (flywheel effect) can drive ionospheric origin FACs and hence actively contribute to the M-I coupling. The present 3-D GCM cannot be applied to the mesoscale rapid localised response of the thermosphere due to the statistical nature of these models, and because of the lack of an adequately dense global observation network.

From the observational point of view, most of the relevant physical parameters are related to each other and need to be measured simultaneously and independently in 3-D space and time, because the relationship reveals the nature of the physical mechanisms. In doing so, the combination of ground-based remote and satellite-borne in situ observations is essential. For example, THEMIS and the Canadian ground-based network conjugately observe largescale processes in order to research the development of auroral substorms. The future Swarm satellites together with the ground-based MIRACLE and ALIS networks in Scandinavia are covering a smaller area, but their much denser network makes it possible to study mesoscale phenomena such as auroral surges and arcs, upwelling of the neutral atmosphere, etc. It should again be noted that only the combination of complementary instruments and well coordinated networks with optimum temporal and spatial scale for each phenomenon can solve these questions.

Also important are the new observation methods with new techniques such as radar interferometry using radars like EISCAT 3-D, in order to investigate small scale phenomena such as black aurora, arcs and ion outflow; and the combined GPS, NIMS and Tsykada tomography with dense regional receiver networks to obtain instantaneous 3-D electron density distribution both in F and E-Region, possibly enabling us to derive regional 3-D conductivities. For the latter and monochromatic auroral images, further progress of the tomography method is challenging but indispensable. Necessary additions to the instrumentation listed above are, for example, a new type of VHF radar that can measure the electric field simultaneously on a mesoscale region at different altitudes in E-Region with a time resolution of a few seconds, plus a corresponding F-Region measurement. The instantaneous comparison of the spatial electric field distribution at 
different altitudes would, together with corresponding neutral wind observations, enable scientists to separate effects of neutral winds and polarisation charges to electric fields, and to observe induced electric fields. Since the electric field at different altitudes is an input required for the 3-D extensions of several electromagnetic data analysis techniques as mentioned in "Potential extension of the techniques to 3-D" in Sect. 3.2.1, such a radar would provide input data and therefore allow for the application of these techniques in 3-D. Further necessary instrumention additions are, e.g. instantaneous 3-D neutral wind measurements by means of the combination of FPI, optical imager, MF/meteor radar, and lidar instruments.

Finally, the coordination will have to be done in a systematic manner, and needs more international collaboration, for which frames such as CAWSES-2, ICESTAR and IPY/IHY will be highly useful.

Acknowledgements. This publication is a result of three meetings of an international science team on ionospheric modelling at the International Space Science Institute (ISSI), Bern, Switzerland. We are grateful to ISSI for their hospitality during these meetings and for the support that made them possible.

Topical Editor M. Pinnock thanks I. McCrea and another anonymous referee for their help in evaluating this paper.

\section{References}

Aikio, A. T., Blomberg, L. G., Marklund, G. T., and Yamauchi, M.: On the origin of the high-altitude electric field fluctuations in the auroral zone, J. Geophys. Res. 101, 27 157-27 170, 1996.

Amm, O. and Viljanen, A.: Ionospheric disturbance magnetic field continuation from the ground to the ionosphere using spherical elementary current systems, Earth, Planets Space, 51, 431-440, 1999.

Amm, O., Janhunen, P., Kauristie, K., Opgenoorth, H. J., Pulkkinen, T. I., and Viljanen, A.: Mesoscale ionospheric electrodynamics observed with the MIRACLE network: 1 . Analysis of a pseudobreakup spiral, J. Geophys. Res., 106, 24 675-24 690, 2001.

Amm, O.: Direct determination of the local ionospheric Hall conductance distribution from two-dimensional electric and magnetic field data: Application of the method using models of typical ionospheric electrodynamic situations, J. Geophys. Res., 100, 21 473-21 488, 1995.

Amm, O.: Ionospheric elementary current systems in spherical coordinates and their application, J. Geomagn. Geoelectr., 49, 947955, 1997.

Amm, O.: Method of characteristics in spherical geometry applied to a Harang discontinuity situation, Ann. Geophys., 16, 413-424, 1998, http://www.ann-geophys.net/16/413/1998/.

Amm, O.: The method of characteristics for calculating ionospheric electrodynamics from multi-satellite and groundbased radar data, J. Geophys. Res., 107(A10), 1270, doi:10.1029/2001JA005077, 2002.

Amm, O., Aksnes, A., Stadsnes, J., Østgaard, N., Vondrak, R. R., Germany, G. A., Lu, G., and Viljanen, A.: Mesoscale ionospheric electrodynamics of omega bands determined from ground-based electromagnetic and satellite optical observations, Ann. Geophys., 23, 325-342, 2005,

http://www.ann-geophys.net/23/325/2005/.

Anderson, B. J., Takahashi, K., Kamei, T., Waters, C. L., and Toth, B. A.: Birkeland current system key parameters derived from Iridium observations: Method and initial validation results, J. Geophys. Res., 107(A6), 1079, doi:10.1029/2001JA000080, 2002.

Aruliah, A. L., Griffin, E. M., Aylward, A. D., Ford, E. A. K., Kosch, M. J., Davis, C. J., Howells, V. S. C., Pryse, S. E., Middleton, H. R., and Jussila, J.: First direct evidence of meso-scale variability on ion-neutral dynamics using co-located tristatic FPIs and EISCAT radar in Northern Scandinavia, Ann. Geophys., 23, 147-162, 2005,

http://www.ann-geophys.net/23/147/2005/.

Aruliah, A. L., Mueller-Wodarg, I. C. F., and Schoendorf, J.: The consequences of geomagnetic history on the high-latitude thermosphere and ionosphere: Averages, J. Geophys. Res., 104, $28073-28088,1999$.

Aruliah, A. L. and Griffin, E.: Evidence of meso-scale structures in the high-latitude thermosphere, Ann. Geophys., 19, 37-46, 2001, http://www.ann-geophys.net/19/37/2001/.

Aso, T., Steen, Å., Brändström, U., Gustavsson, B., Urashima, A., Ejiri, M.: ALIS, A State-of-the-Art Optical Observation Network for the Exploration of Polar Atmospheric Processes, Adv. Space Res., 26(6), 917-924, 2000.

Baker, J. B. H., Greenwald, R. A., Ruohoniemi, J. M., Förster, M., Paschmann, G., Donovan, E. F., Tsyganenko, N. A., Quinn, J. M., and Balogh, A.: Conjugate comparison of Super Dual Auroral Radar Network and Cluster electron drift instrument measurements of $E \times B$ plasma drift, J. Geophys. Res., 109, A01209, doi:10.1029/2003JA009912, 2004.

Biondi, M. A., Sazykin, S. Y., Fejer, B. G., Meriwether, J. W., Fesen, C. G.: Equatorial and low latitude thermospheric winds: Measured quiet time variations with season and solar flux from 1980 to 1990, J. Geophys. Res., 104(A8), 17 091-17 106, 1999.

Blixt, E. M. and Kosch, M. J.: Coordinated optical and EISCAT observations of black aurora, Geophys. Res. Lett., 31, L06813, doi:10.1029/2003GL019244, 2004.

Brekke, A.: Physics of the Upper Polar Atmosphere, Wiley-Praxis Series in Atmospheric Physics, Chichester, United Kingdom, 1997.

Buchert, S. and Budnik, F.: Field-aligned current distributions generated by a divergent Hall current, Geophys. Res. Lett., 24, 297300, 1997.

Buchert, S.: Magneto-optical Kerr effect for a dissipative plasma, J. Plasma Phys., 59, 39-55, 1998.

Conde, M. and Smith, R. W.: Spatial structure in the thermospheric horizontal wind above Poker Flat, Alaska, during solar minimum, J. Geophys. Res., 103(A5), 9449-9472, 1998.

Courant, R. and Hilbert, D.: Methods of mathematical physics, vol. 2, John Wiley and sons, New York, 1962.

Cowley, S. W. H. and Lockwood, M.: Time-dependent flows in the coupled solar wind-magnetosphere-ionosphere system, Adv. Space Res., 18(8), 141-150, 1996.

Dickinson, R. E., Ridley, E. C., and Roble, R. G.: A threedimensional general circulation model of the thermosphere, J. Geophys. Res., 86, 1499-1512, 1981.

Dreher, J.: On the self-consistent description of dynamic 
magnetosphere-ionosphere coupling phenomena with resolved ionosphere, J. Geophys. Res., 102, 85-94, 1997.

Escoubet, C. P., Fehringer, M., and Goldstein, M.: The Cluster mission, Ann. Geophys., 19, 1197-1200, 2001, http://www.ann-geophys.net/19/1197/2001/.

Fujii, R., Hoffman, R. A., Anderson, P. C., Craven, J. D., Sugiura, M., Frank, L. A., and Maynard, N.: Electrodynamic parameters in the nighttime sector during auroral substorms, J. Geophys. Res., 99, 6093-6112, 1994.

Fujii, R., Nozawa, S., Matuura, N., and Brekke, A.: Study on neutral wind contribution to the electrodynamics in the polar ionosphere using EISCAT CP-1 data, J. Geophys. Res., 103, 14 731$14740,1998$.

Fujii, R., Oyama, S., Buchert, S. C., Nozawa, S., and Matuura, N.: Field-aligned ion motions in the $\mathrm{E}$ and $\mathrm{F}$ regions, J. Geophys. Res., 107(A5), 1049, doi:10.1029/2001JA900148, 2002.

Fuller-Rowell, T. J. and Rees, D.: A three-dimensional timedependent global model of the thermosphere, J. Atmos. Sci., 37, 2545-2567, 1980.

Gardner, C. S.: Performance capabilities of middle-atmosphere temperature lidars: comparison of $\mathrm{Na}, \mathrm{Fe}, \mathrm{K}, \mathrm{Ca}, \mathrm{Ca}+$, and Rayleigh systems, Appl. Optics, 43(25), 4941-4956, 2004.

Gary, J. B., Heelis, R. A., Hanson, W. B., and Slavin, J. A.: Fieldaligned Poynting flux observations in the high-latitude ionosphere, J. Geophys. Res., 99(A6), 11 417-11 428, 1994.

Gjerloev, J. W. and Hoffman, R. A.: Currents in auroral substorms, J. Geophys. Res., 107(A8), 1163, doi:10.1029/2001JA000194, 2002.

Glassmeier, K.-H.: Reflection of MHD-waves in the PC4-5 period range at ionospheres with non-uniform conductivity distributions, Geophys. Res. Lett., 10, 678-681, 1983.

Greenwald, R. A., Baker, K. B., Dudeney, J. R., Pinnock, M., Jones, T. B., Thomas, E. C., Villain, J.-P., Cerisier, J.-C., Senior, C., Hanuise, C., Hunsucker, R. D., Sofko, G., Koehler, J., Nielsen, E., Pellinen, R., Walker, A. D. M., Sato, N., and Yamagishi, H.: DARN/ SuperDARN: A global view of the dynamics of highlatitude convection, Space Sci. Rev., 71, 761-796, 1995.

Grydeland, T., Chau, J. L., La Hoz, C., and Brekke, A.: An imaging interferometry capability for the EISCAT Svalbard Radar, Ann. Geophys., 23, 221-230, 2005,

http://www.ann-geophys.net/23/221/2005/.

Gustavsson, B., Sergienko, T., Rietveld, M. T., Honary, F., Steen, A., Brandstrom, B. U. E., Leyser, T. B., Aruliah, A. L., Aso, T., Ejiri, M., and Marple, S.: First tomographic estimate of volume distribution of HF-pumped enhanced airglow emission, J. Geophys. Res., 106, 29 105-29 124, 2001.

Hedin, A. E., Fleming, E. L., Manson, A. H., Schmidlin, F. J., Avery, S. K., Clark, R. R., Franke, S. J., Fraser, G. J., Tsuda, T., Vial, F., and Vincent, R. A.: Empirical wind model for the upper, middle and lower atmosphere, J. Atmos. Terr. Phys., 58, 14211447, 1996.

Hedin, A. E, Mayr, H. G., Reber, C. A., Spencer, N. W., and Carignan, G. R.: Empirical model of global thermospheric temperature and composition based on data from the OGO 6 quadrupole mass spectrometer, J. Geophys. Res., 79, 215-225, 1974.

Hoffman, R. A., Fujii, R., and Sugiura, M.: Characteristics of the field-aligned current system in the nighttime sector during auroral substorms, J. Geophys. Res., 99, 21 303-21 325, 1994.

Inhester, B., Untiedt, J., Segatz, M., and Kürschner, M.: Direct de- termination of the local ionospheric Hall conductance distribution from two-dimensional electric and magnetic field data, J. Geophys. Res., 97, 4073-4083, 1992.

Innis, J. L., Greet, P. A., Murphy, D. J., Conde, M. G., and Dyson, P. L.: A large vertical wind in the thermosphere at the auroral oval/polar cap boundary seen simultaneously from Mawson and Davis, Antarctica, J. Atmos. Solar-Terr. Phys., 61, 1047-1058, 1999.

Jakowski, N., Wilken, V., and Mayer, C.: Space weather monitoring by GPS measurements on board CHAMP, Space Weather, 5, S08006, doi:10.1029/2006SW000271, 2007.

Kamide, Y. and Kokubun, S.: Two-component auroral electrojet: Importance for substorm studies, J. Geophys. Res., 101, 13027 13 046, 1996.

Kamide, Y., Richmond, A. D., and Matsushita, S.: Estimation of ionospheric electric fields, ionospheric currents, and fieldaligned currents from ground magnetic records, J. Geophys. Res., 86, 801-813, 1981.

Kataoka, H.: Study of auroral electrodynamics using 2-d HallMHD simulations, MSc Thesis, Nagoya University, 2001.

Killeen, T. L., Hays, P. B., Carignan, G. R., Heelis, R. A., Hanson, W. B., Spencer, N. W., and Brace, L. H.: Ion-Neutral Coupling in the High Latitude F-Region: Evaluation of Ion Heating Terms from Dynamics Explorer 2, J. Geophys. Res., 89, 7495-7508, 1984.

Kirkwood, S.: Lower thermosphere mean temperatures, densities, and winds measured by EISCAT: Seasonal and solar cycle effects, J. Geophys. Res., 101(A3), 5133-5148, 1996.

Kishore, P., Namboothiri, S. P., Igarashi, K., Murayama, Y., and Watkins, B. J.: MF radar observations of mean winds and tides over Poker Flat, Alaska (65.1 $\left.{ }^{\circ} \mathrm{N}, 147.5^{\circ} \mathrm{W}\right)$, Ann. Geophys., 20, 679-690, 2002, http://www.ann-geophys.net/20/679/2002/.

Kurihara, J. and Oyama, K.-I.: Rocket-borne instrument for measuring vibrational-rotational temperature and density in the lower thermosphere, Rev. Sci. Instr., 76(8), 083101-083101-6, 2005.

Lee, J. K., Kamalabadi, F., and Makela, J.: Localized three-dimensional ionoshereic tomography with GPS ground receiver measurements, Radio Sci., 42, RS4018, doi:10.1029/2006RS003543, 2007.

Liu, H., Lühr, H., Henize, V., and Köhler, W.: Global distribution of the thermospheric total mass density derived from CHAMP, J. Geophys. Res., 110, A04301, doi:10.1029/2004JA010741, 2005.

Lotko, W.: Inductive magnetosphere-ionosphere coupling, J. Atmos. Terr. Phys,.., 66, 1443-1456, 2004.

Lu, G., Richmond, A. D., Emery, B. A., and Roble, R. G.: Magnetosphere-ionosphere-thermosphere coupling: Effect of neutral winds on energy transfer and field-aligned current, J. Geophys. Res., 100(A10), 19643-19660, 1995.

Lühr, H., Aylward, A., Buchert, S. C., Pajunpää, A., Pajunpää, K., Holmboe, T., and Zalewskia, S. M.: Westward moving dynamic substorm features observed with the IMAGE magnetometer network and other ground-based instruments, Ann. Geophys., 16, 425-440, 1998, http://www.ann-geophys.net/16/425/1998/.

Lühr, H., Rother, M., Köhler, W., Ritter, P., and Grunwaldt, L.: Thermospheric up-welling in the cusp region: Evidence from CHAMP observations, Geophys. Res. Lett., 31, L06805, doi:10.1029/2003GL019314, 2004.

Lui, A. T. Y. and Kamide, Y.: A fresh perspective of the substorm current system and its dynamo, Geophys. Res. Lett., 30(18), 
1958, doi:10.1029/2003GL017835, 2003.

Lyons, L. R., Walterscheid, R. L., and Killeen, T. L.: The neutral wind 'flywheel' as a source of quiet-time, polar-cap currents, Geophys. Res. Lett., 12, 101-104, 1985.

Lysak, R. L. and Song, Y.: A three-dimensional model of the propagation of Alfvén waves through the auroral ionosphere: First results, Adv. Space Res., 28, 813-822, 2001.

Lysak, R. L.: Propagation of Alfvén waves through the ionosphere: Dependence on ionospheric parameters, J. Geophys. Res., 104, 10017-10030, 1999.

Mallinckrodt, A. J.: A numerical-simulation of auroral ionospheric electrodynamics, J. Geophys. Res., 90, 409-417 1985.

Manson, A. H., Meek, C. E., Massebeuf, M., Fellous, J. L., and Elford, W. G.: Mean winds of the mesosphere and lower thermosphere $(60-110 \mathrm{~km})$ - A global distribution from radar systems (MF, meteor, VHF), Adv. Space Res., 5(7), 135-144, 1985.

Marklund, G., Karlsson, T., and Clemmons, J.: On low-altitude particle acceleration and intense electric fields and their relationship to black aurora, J. Geophys. Res., 102, 17 509-17 522, 1997.

Matsuo, T., Richmond, A. D., and Lu, G.: Optimal interpolation analysis of high-latitude ionospheric electrodynamics using empirical orthogonal functions: Estimation of dominant modes of variability and temporal scales of large-scale electric fields, J. Geophys. Res., 110, A06301, doi:10.1029/2004JA010531, 2005.

McPherron, R. L., Russel, C. T., and Aubry, M. P.: Satellite studies of magnetospheric substorms on August 15, 1968: 9. Phenomenological model for substorms, J. Geophys. Res., 78, 31313149, 1973 .

Millward, G. H., Müller-Wodarg, I. C. F., Aylward, A. D., FullerRowell, T. J., Richmond, A. D., and Moffett, R. J.: An investigation into the influence of tidal forcing on $\mathrm{F}$ region equatorial vertical ion drift using a global ionosphere-thermosphere model with coupled electrodynamics, J. Geophys. Res., 106(A11), $24733-24744,2001$.

Mitchell, C. N. and Spencer, P. S. J.: A three-dimensional timedependent algorithm for ionospheric imaging using GPS, Ann. Geophys., 46(4), 687-696, 2003.

Murison M., Richmond, A., Matsushita, S., and Baumjohann, W.: Estimation of ionospheric electric fields and currents from a regional magnetometer array, J. Geophys. Res., 90, 3525-3530, 1985.

Nicolls, M. J. and Heinselman, C. J.: Three-dimensional measurements of traveling ionospheric disturbances with the Poker Flat Incoherent Scatter Radar, Geophys. Res. Lett., 34, L21104, doi:10.1029/2007GL031506, 2007.

Nygrén, T., Taylor, M. J., Lehtinen, M. S., and Markkanen, M.: Application of tomographic inversion in studying airglow in the mesopause region, Ann. Geophys., 16, 1180-1189, 1998, http://www.ann-geophys.net/16/1180/1998/.

Ober, D. M., Wilson, G. R., Maynard, N. C., Burke, W. J., and Siebert, K. D.: MHD simulation of the transpolar potential after a solar-wind density pulse, Geophys. Res. Lett., 33, L04106, doi:10.1029/2005GL024655, 2006.

Richmond, A. D. and Lu, G.: Upper-atmospheric effects of magnetic storms: a brief tutorial, J. Atmos. Terr. Phys., 62, 11151127,2000

Richmond, A. D. and Kamide, Y.: Mapping electrodynamic features of the high-latitude ionosphere from localized observations: Technique, J. Geophys. Res., 93, 5741-5759, 1988.
Richmond, A. D., Ridley, E. C., and Roble, R. G.: A thermosphere/ionosphere general circulation model with coupled electrodynamics, Geophys. Res. Lett., 19, 601-604, 1992.

Rishbeth, H., Ganguly, S., and Walker, J. C. G.: Field-aligned and field-perpendicular velocities in the ionospheric F2-layer, J. Atmos. Terr. Phys., 40, 767-784, 1978.

Ritter, P. and Lühr, H.: Curl-B technique applied to Swarm constellation for determining field-aligned currents, Earth Planets Space, 58, 463-476, 2006

Rostoker, G. and Boström, R.: A mechanism for driving the gross Birkeland current configuration in the auroral oval, J. Geophys. Res., 81, 234-244, 1976.

Schlegel, K., Lühr, H., St.Maurice, J.-P., Crowley, G., and Hackert, C.: Thermospheric density structures over the polar regions observed with CHAMP, Ann. Geophys., 23, 1659-1672, 2005, http://www.ann-geophys.net/23/1659/2005/.

Scholer, M.: On the motion of artificial ion clouds in the magnetosphere, Planet. Space Sci., 18, 977-1004, 1970

Semeter, J., Lummerzheim, D., and Haerendel, G.: Simultaneous multispectral imaging of the discrete aurora, J. Atmos. SolarTerr. Phys., 63(18), 1981-1992, 2001.

Shepherd, G. G., Thuillier, G., Gault, W. A., Solheim, B. H., Hersom, C., Alunni, J. M., Brun, J.-F., Brune, S., Charlot, P., and Cogger, L. L.: WINDII, the wind imaging interferometer on the Upper Atmosphere Research Satellite, J. Geophys. Res., 98(D6), 10725-10750, 1993.

Smith, R.: Vertical winds: A tutorial, J. Atmos. Sol. Terr. Phys., 60, 1425-1434, 1998.

Spencer, N. W., Wharton, L. E., Niemann, H. B., Hedin, A. E. Carrignan, G. R., and Maurer, J. C.: The Dynamics Explorer Wind and Temperature Spectrometer, Space Sci. Instr., 5, 417428, 1981.

Stolle, C., Jakowski, N., Schlegel, K., and Rietveld, M.: Comparison of high latitude electron density profiles obtained with the GPS radio occultation technique and EISCAT measurements, Ann. Geophys., 22, 2015-2022, 2004, http://www.ann-geophys.net/22/2015/2004/.

Stolle, C., Schlüter, S., Heise, S., Jacobi, Ch., Jakowski, N., and Raabe, A.: A GPS based three-dimensional ionospheric imaging tool: process and assessment, Adv. Space Res., 38, 2313-2317, doi:10.1016/j.asr.2006.05.016, 2006

Sullivan, J. M., Ivchenko, N., Lockwood, M., Grydeland, T., Blixt, E. M., and Lanchester, B. S.: Phase calibration of the EISCAT Svalbard Radar interferometer using optical satellite signatures, Ann. Geophys., 24, 2419-2427, 2006, http://www.ann-geophys.net/24/2419/2006/.

Taylor, M. J., Hapgood, M. A., and Rothwell, P.: Observations of gravity wave propagation in the $\mathrm{OI}(557.7 \mathrm{~nm}), \mathrm{Na}(589.2 \mathrm{~nm})$ and the near infra-red $\mathrm{OH}$ nightglow emissions, Planet. Space Sci., 35, 413-427, 1987.

Thayer, J. P., Vickrey, J. F., Heelis, R. A., and Gary, J. B.: Interpretation and modeling of the high-latitude electromagnetic energy flux, J. Geophys. Res., 100(A10), 19715-19728, 1995.

Thayer, J. P.: Height-resolved Joule heating rates in the highlatitude $\mathrm{E}$ region and the influence of neutral winds, J. Geophys. Res., 103(A1), 471-487, 1998.

Toivanen P., Koskinen, H., and Pulkkinen, T.: Mapping between the ionospheric and the tail electric fields in a time-dependent Earth's magnetosphere, J. Geophys. Res., 103, 9153-9164, 1998. 
Vanhamäki H., Amm, O., and Viljanen, A.: Role of inductive electric fields and currents in dynamical ionospheric situations, Ann. Geophys., 25, 437-455, 2007, http://www.ann-geophys.net/25/437/2007/.

Vanhamäki, H., Amm, O., and Viljanen, A.: New method for solving inductive electric fields in the ionosphere, Ann. Geophys., 24, 2573-2582, 2006, http://www.ann-geophys.net/24/2573/2006/.

Vanhamäki, H. and Amm, O.: A new method to estimate ionospheric electric fields and currents using data from a local ground magnetometer network, Ann. Geophys., 25, 1141-1156, 2007, http://www.ann-geophys.net/25/1141/2007/.

Vasyliunas, V.: Mathematical models of magnetospheric convection and its coupling to the ionosphere, in:, Particles and fields in the magnetosphere, edited by: McCormac, B M. , Reidel, Hingham, MA, 1970.

Williams, P. J. S., Virdi, T. S., Crowley, G., McCrea, I., and Schlegel, K.: The generation and propagation of atmospheric gravity waves observed during the Worldwide Atmospheric Gravity-wave Study (WAGS), J. Atmos. Terr. Phys., 50, 323338, 1988.

Yin, P. and Mitchell, C. N.: Use of radio-occultation data for ionospheric imaging during the April 2002 disturbances, GPS Solutions, 9(2), 156-163, 2005.
Yoshikawa, A. and Itonaga, M.: The nature of reflection and mode conversion of MHD waves in the inductive ionosphere: Multistep mode conversion between divergent and rotational electric fields, J. Geophys. Res., 105, 10 565-10 584, 2000.

Yoshikawa, A. and Itonaga, M.: Reflection of shear Alfvén waves at the ionosphere and the divergent Hall current, Geophys. Res. Lett., 23, 101-104, 1996.

Yoshikawa, A., Itonaga, M., Fujita, S., Nakata, H., and Yumoto, K.: Eigenmode analysis of field line oscillations interacting with the ionosphere-atmosphere-solid earth electromagnetic coupled system, J. Geophys. Res., 104, 28 437-28 457, 1999.

Yoshikawa, A., Obana, Y., Shinohara, M., Itonaga, M., and Yumoto, K.: Hall-induced inductive shielding effect on geomagnetic pulsations, Geophys. Res. Lett., 29, 1266, doi:10.1029/2001g1013610, 2002.

Yoshikawa, A.: How does the ionospheric rotational Hall current absorb the increasing energy from the fieldaligned current system?, Geophys. Res. Lett., 29, 1133, doi:10.1029/2001GL014125, 2002.

Zhu, H., Otto, A., Lummerzheim, D., Rees, M. H., and Lanchester, B. S.: Ionosphere-magnetosphere simulation of smallscale structure and dynamics, J. Geophys. Res., 106, 1795-1806, doi:10.1029/1999JA000291, 2001. 